\title{
AVALIAÇÃO DA RESISTÊNCIA MECÂNICA A COMPRESSÃO NO COQUE*
}

Guilherme Liziero Ruggio da Silva ${ }^{1}$ lara Patricia Vieira de Oliveira ${ }^{2}$ Lorena Cristina Amorim Moura ${ }^{3}$ Paulo Santos Assis ${ }^{4}$

\section{Resumo}

O coque desempenha três principais funções no Alto-Forno sendo elas: física, térmica e química, em se tratando do papel físico, a função estrutural é de primordial importância, pois não pode ser assumida por outro combustível, com isto as indústrias avaliam a resistência mecânica a frio para garantir uma marcha estável no reator, porém os ensaios padronizados não são suficientes para avaliar a resistência do coque. Neste contexto este trabalho desenvolveu uma metodologia para avaliar de forma individual a resistência mecânica a compressão do coque nas granulometrias típicas do coque metalúrgico e como os principais defeitos, poros e trincas governam a resistência do material. Foram realizados testes de compressão, análise de microestrutura, microtextura, inspeção visual de trincas, MEV. Os resultados das análises realizadas no coque mostraram que a tensão média de ruptura aumenta com o aumento da granulometria.

Palavras-chave: Resistência mecânica; Porosidade; Trincas; Tensão de ruptura

\section{EVALUATION OF STRENGTH MECHANICAL COMPRESSION OF COKE}

\begin{abstract}
I The coke plays three main roles in the Blast Furnace: physical, thermal and chemical, when it comes to the physical role, the structural function is of primary importance because it can not be assumed by other fuels, with this the industries evaluate the mechanical resistance To ensure a steady gait in the reactor, but the standardized tests are not sufficient to evaluate the resistance of the coke. In this context, this work developed a methodology to individually evaluate the mechanical strength of coke compression in the typical granulometry of metallurgical coke and how the main defects, pores and cracks govern the strength of the material. Compression tests, microstructure analysis, microtexture, visual inspection of cracks, SEM were performed. The results of the analyzes performed on the coke showed that the average tensile stress increases with the increase of the granulometry.
\end{abstract}

Keywords: Strenght mechanical; Porosity; Crack; Rupture tension.

Doutor Engenharia dos Materiais REDEMAT/UFOP, Gerdau Ouro Branco, Brasil. Graduanda em Engenharia Metalúrgica, Instituto Federal de Minas Gerais, IFMG. Graduanda em Engenharia Metalúrgica, Instituto Federal de Minas Gerais, IFMG.

Prof. Dr. Titular da Escola de Minas da UFOP - REDEMAT. 


\section{INTRODUÇÃO}

O coque metalúrgico produzido a partir de misturas de carvões coqueificáveis desempenha três funções principais no Alto-Forno sendo elas apresentadas na figura 1.

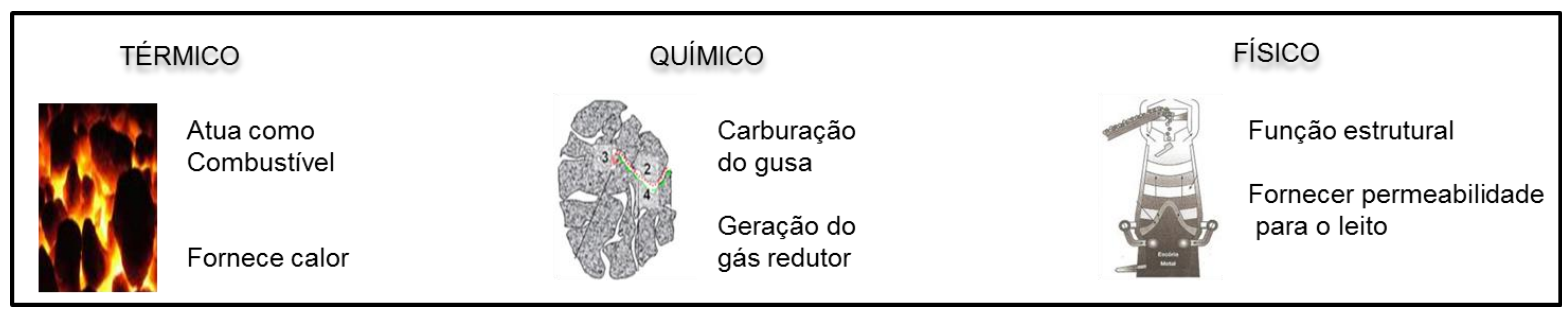

Figura 1: Principais funções que o coque desempenha no Alto-Forno

Os papéis químico e térmico do coque podem ser substituídos, em parte, por outros combustíveis, já o papel físico do coque não pode ser assumido por nenhum outro combustível, pois é considerado de primordial importância para uma operação eficiente do Alto-Forno.

Para assegurar que a função estrutural do coque seja desempenhada com efetividade, o setor siderúrgico avalia a resistência mecânica à frio, através de ensaios como Drum Test, Micum ${ }^{40}{ }_{10}$, IRSID ${ }^{20}{ }_{10}$, no Brasil o mais utilizado é o $D I^{150}{ }_{15}$, estes são importantes índices para determinar a qualidade da matéria prima, garantindo uma operação estável no Alto-Forno. A Figura 2 exemplifica os parâmetros físicos para avaliação da resistência mecânica a frio e os princípios de fragmentação das partículas.

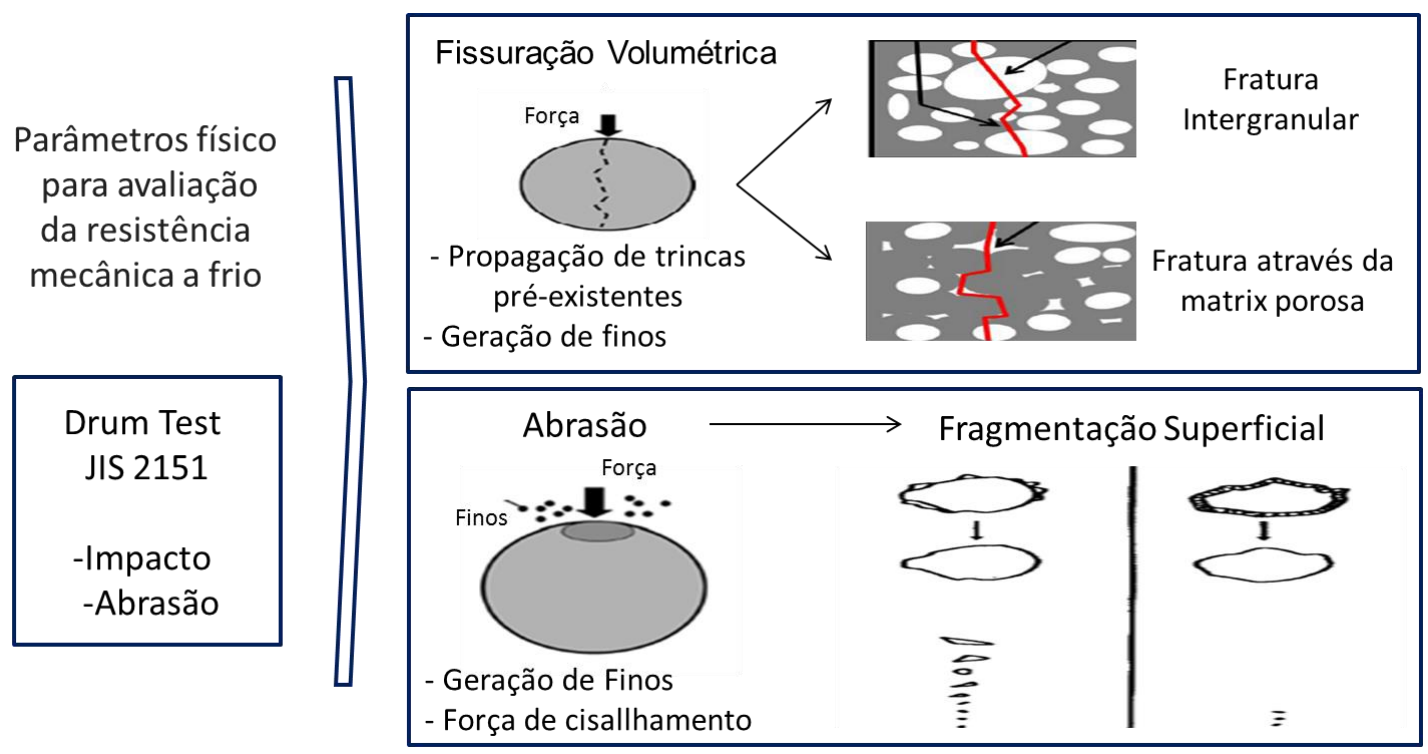

Figura 2: Princípios de fragmentação das partículas de coque

Estes parâmetros que são utilizados, não são suficientes para determinar a resistência mecânica do coque, razão pela qual este trabalho desenvolveu uma metodologia para avaliar a resistência mecânica a compressão no coque. Esta nova abordagem é devida a forma como o coque sofre esforços de compressão dentro do Alto-Forno e nos Silos. 
Sendo o coque um material particulado, poroso, heterogêneo e anisotrópico, seu estudo envolve uma abordagem diferente das usadas na resistência dos materiais e mecânica da fratura, uma vez que o coque não possui formatos regulares e ainda apresenta defeitos como poros e trincas, o que dificulta 0 conhecimento das distribuições internas dos esforços.

O comportamento das partículas que apresentam características diferentes, tais como: tamanho, forma e estrutura interna; já foi estudada por diversos autores como King (2001), Austin (1994), entre outros Carvalho (2013). Segundo Tavares (1997), existe uma variabilidade intrínseca relacionada à fratura em populações de partículas, ou seja, em partículas do mesmo material, com mesma faixa granulométrica é possível encontrar uma grande variabilidade de partículas com diferentes resistências, sendo algumas mais fáceis de fratura que outras. Esta é uma das maiores dificuldades encontradas para caracterizar a energia necessária para fraturar uma partícula de coque.

Neste contexto, este trabalho visa avaliar a resistência mecânica a compressão de forma individual nas partículas de coque nas diferentes faixas granulométricas que alimentam o Alto-Forno na Usina Gerdau, Ouro Branco, pois uma variabilidade na distribuição de tamanhos implica em variações no comportamento mecânico. A Figura 3 ilustra os tipos de fragmentação que ocorrem nas partículas quando submetidas à compressão.

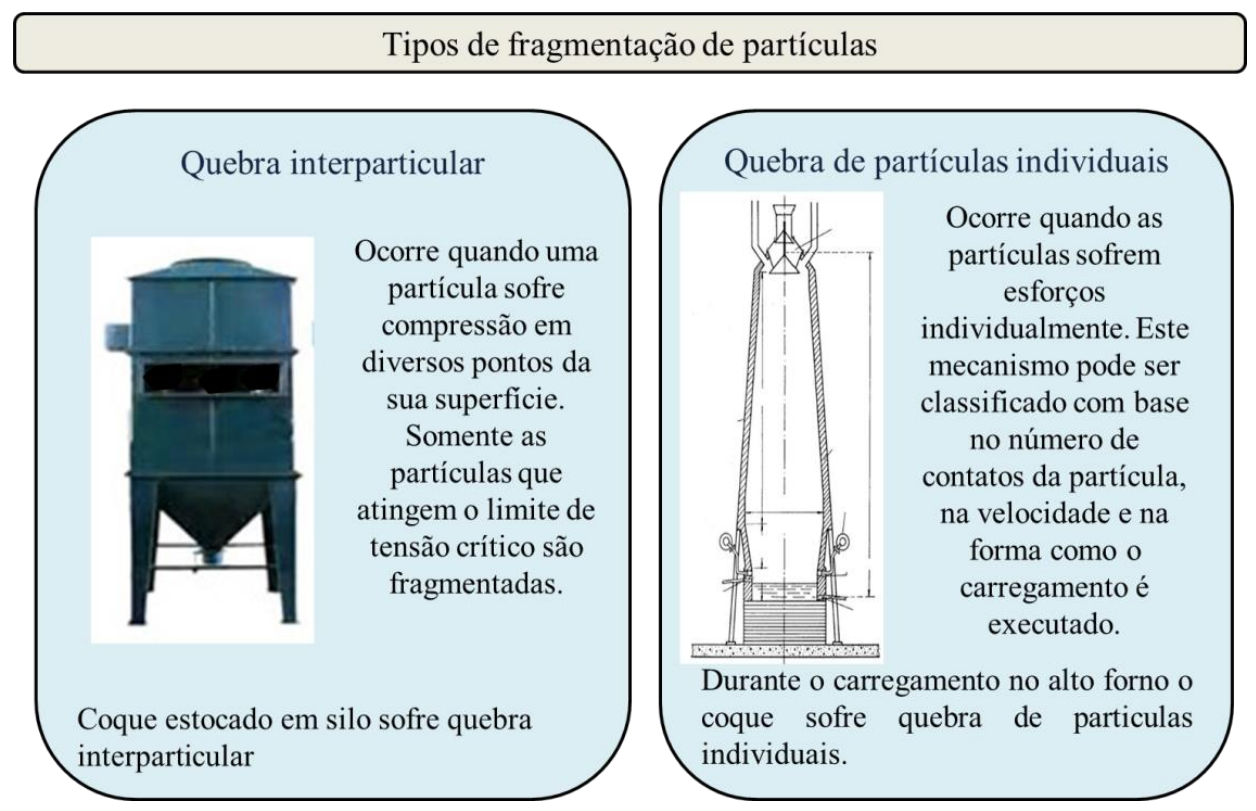

Figura 3: Diferentes tipos de fragmentação que ocorrem quando partículas são expostas a compressão.

Este trabalho também aborda como a distribuição dos dois principais defeitos, poros e trincas, governam todo o processo de fratura, fazendo com que a tenacidade do coque seja reduzida.

De acordo com Silveira (2012), quando um material que contém uma trinca (defeito) é tensionado, esta trinca age como um concentrador de esforços em sua extremidade resultando em sua propagação através da criação de novas superfícies.

Segundo Xinget, (2013), o coque metalúrgico sendo um material de alta porosidade possui sua resistência mecânica dependente da estrutura do poro bem como da resistência da parede dos poros. 
Portanto neste trabalho o coque é caracterizado através da análise de sua microestrutura e microtextura. $O$ termo microestrutura do coque refere-se a distribuição física e espacial da massa que constitui o coque, ou seja, sua porosidade, tamanho dos poros e espessura das paredes dos poros. A microtextura por sua vez, refere-se à natureza do carbono do coque, sua organização cristalina e grau de anisotropia (COIN,1987).

Segundo Gray e Devanney, (1986), o interesse em se avaliar a microtextura de coques está diretamente relacionado ao fato de poder relacioná-la a propriedades como reatividade e resistência do coque.

\section{MATERIAIS E MÉTODOS}

No presente trabalho, os coques utilizados foram cedidos pela Usina Siderúrgica Gerdau.

Os experimentos necessários à realização deste trabalho foram realizados nos Laboratório da Laminação de Aços Planos e de Matérias Primas da Gerdau Usina Ouro Branco.

Inicialmente foi realizada a amostragem do coque segundo a norma ASTM D 346, seguida de classificação granulométrica nas seguintes peneiras (13.0, 19.0, 25.0, 37.5, 50.0, 63.0, 75.0 e $100.0 \mathrm{~mm})$.

Os testes foram divididos em duas etapas conforme a figura 4.

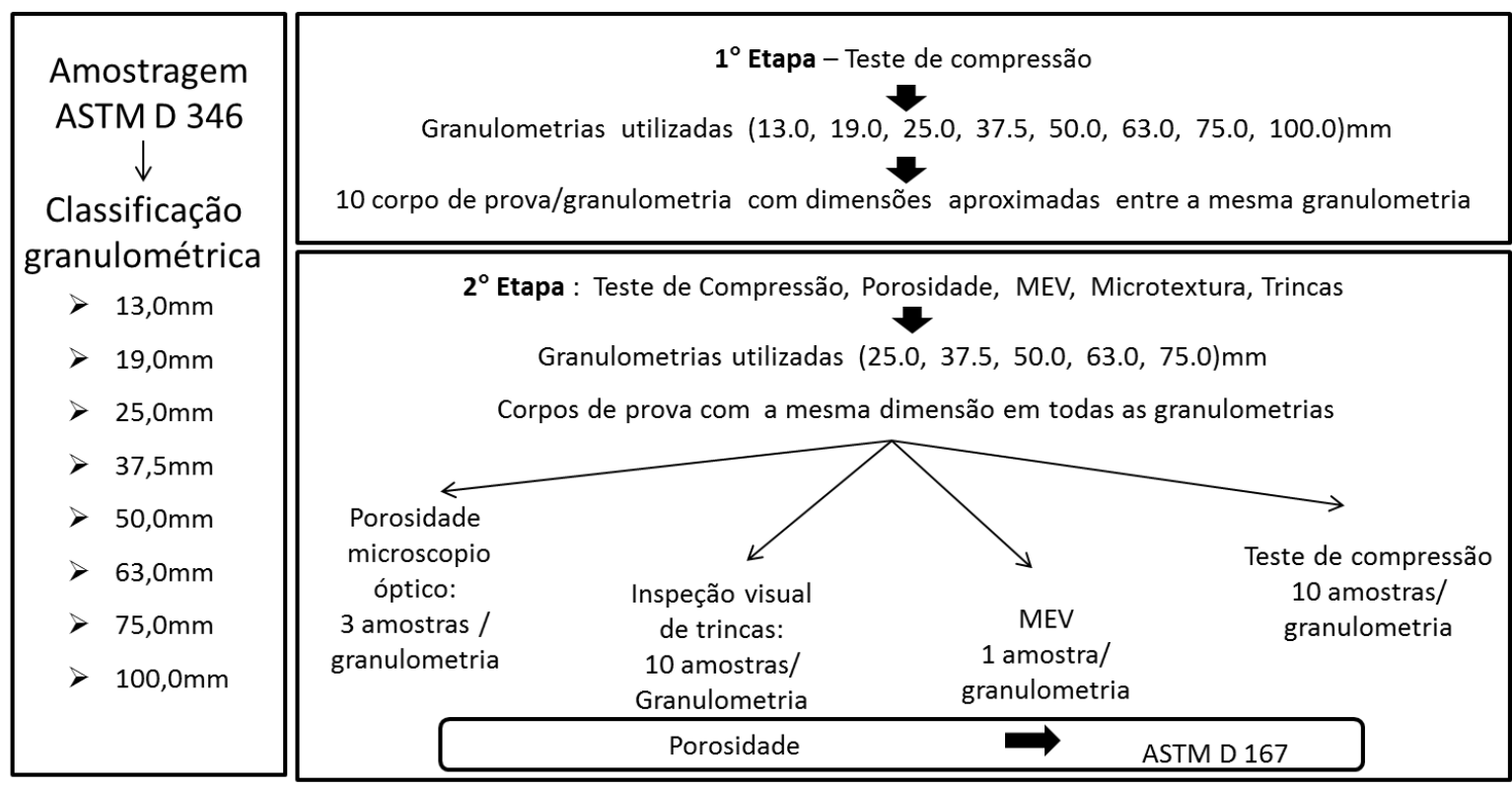

Figura 4: Fluxograma dos testes

\section{1 - Primeira Etapa}

Foram utilizadas todas as granulometrias geradas no peneiramento para a confecção dos corpos de provas com dimensões próximas dentro da mesma granulometria.

\subsection{1 - Análise de resistência a compressão em partícula individual de coque.}

Nesta etapa foram selecionadas aleatoriamente dez peças de coques de cada granulometria. Em seguida os coques foram transformados em corpos de prova, 
com dimensões próximas (densidade, área e volume e a massa) dentro da mesma granulometria, por exemplo, as amostras de $19,0 \mathrm{~mm}$ não têm as mesmas dimensões das amostras de $37,5 \mathrm{~mm}$, conforme ilustra a Figura 5(a).

Os corpos de prova foram submetidos à compressão em uma máquina de ensaio universal da marca Shimadzu com uma célula de carga de $300 \mathrm{kN}$, usando uma velocidade de deslocamento de $2 \mathrm{~mm} / \mathrm{min}$ até que o coque sofra ruptura e obtenha o gráfico com os valores da tensão máxima de ruptura.

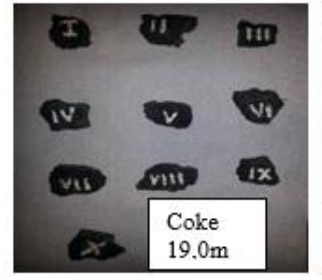

(a)

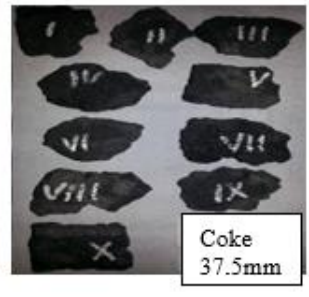

$37.5 \mathrm{~mm}$

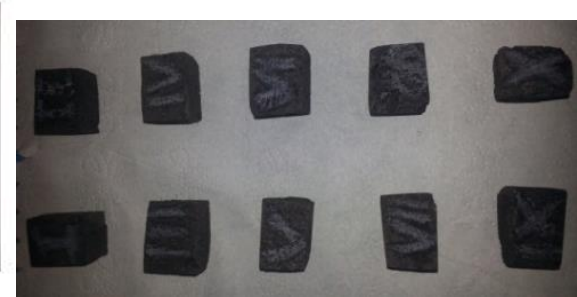

(b)

Figure 5: Dimensões dos corpos de prova utilizados em (a) $1^{\circ}$ Etapa; (b) $2^{\circ}$ Etapa

\section{2 - Segunda Etapa}

$\mathrm{Na}$ segunda etapa, em todos os testes, foram utilizadas as granulometrias típicas de coque metalúrgico. Para a realização das análises, exceto para macroporosidade, foi utilizado corpos de prova com dimensões muito próximas entre todas as faixas granulométricas, conforme ilustra a figura 5(b). Já para o teste de macroporosidade foi utilizado a norma ASTM D167.

\subsection{1 - Análise de resistência a compressão em partícula individual de coque.}

Nesta etapa foram selecionadas aleatoriamente dez peças de coques de cada granulometria, o ensaio de compressão na segunda etapa foi realizado segundo a metodologia utilizada na primeira etapa.

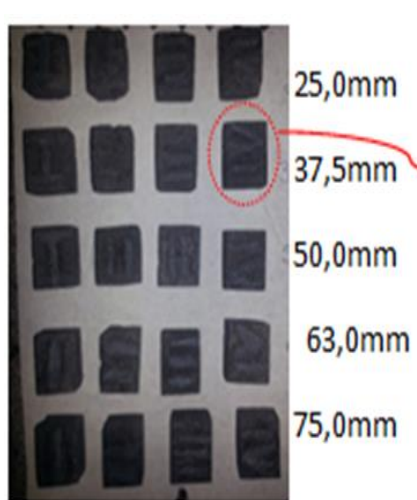

(a)

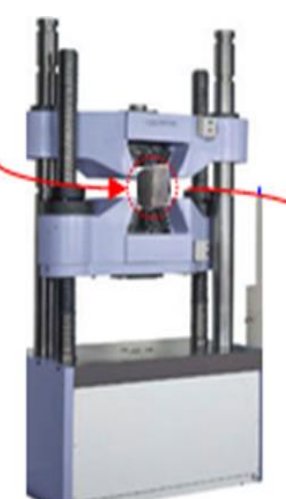

(b)

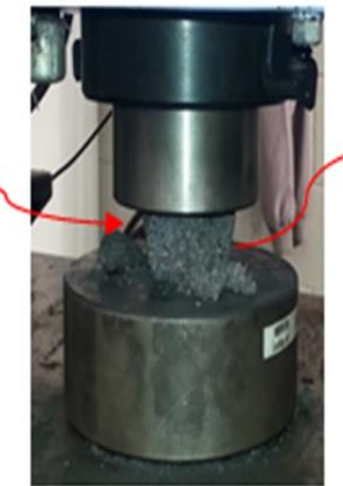

(c)

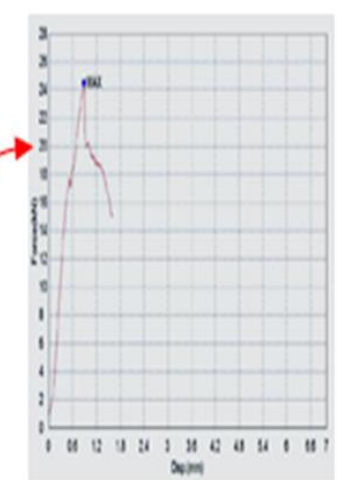

(d)

Figure 6: (a) corpo de prova da $2^{\circ}$ etapa; (b) máquina de ensaio universal; (c) teste de compressão; (d) gráfico tensão de ruptura

\section{Porosidade}

Uma vez que a resistência mecânica está relacionada de forma importante com a porosidade, utilizou duas metodologias diferentes: análise da 
macroporosidade e da microporosidade, com o intuito de conhecer a porosidade dos coques nas diferentes faixas granulométricas.

\section{1 - Análise da macroporosidade segundo a norma ASTM - D 167.}

Foi aplicada a norma ASTM D 167 Standard Test Method for Apparent and True Specific Gravity and Porosity of Lump Coke para todas as granulometrias.

\section{2 - Análise da microporosidade via microscópio óptico.}

Os testes foram realizados da seguinte forma: foram utilizados três corpos de prova para cada granulometria. A análise microscópica foi realizada em um microscópio Leica CTR 6000 equipado com o software Fóssil com um aumento de 50x (sem óleo) e com aumento de 200x. Após o polimento do corpo de prova, avançou-se para análise de microscopia, com aumento de 200x para análise e mensuração da relação matriz/poros das amostras de coque, realizando-se a leitura de 200 pontos, com dimensão de cada passo de $(0,5 \mu \mathrm{m})$.

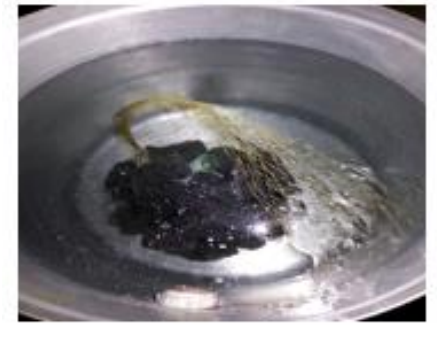

(a)

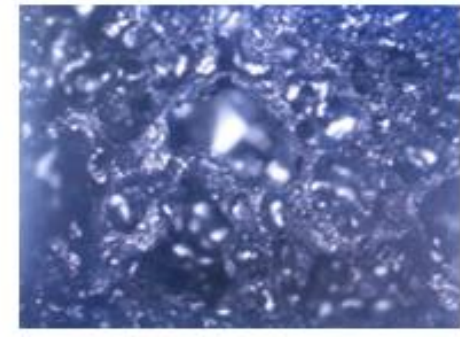

(b)

Figure 7: (a) análise de macroporosidade (b) análise de microporosidade

\section{MEV}

Buscando avaliar as razões e justificar os resultados obtidos referentes a tensão de ruptura do coque nas diferentes granulometrias, foi necessário caracterizações físicas, principalmente avaliar as características dos poros como: tamanho, formato, espessura das paredes e profundidade. O Microscópio Eletrônico de Varredura (MEV) tem se mostrado uma ferramenta eficiente uma vez que a maior profundidade de foco torna possível o uso de amostras polidas.

Foi utilizado um corpo de prova para cada granulometria. As amostras foram levadas ao microscópio eletrônico de varredura modelo FEI INSPECT S50, este equipamento reproduz imagens com aumento de até 2.984.000x. Não foi necessária a metalização da amostra. A amostra foi levada para o porta amostra para digitalização e tratamento das imagens.

\section{Análise de trincas}

Com o intuito de avaliar as macrotrincas nas diferentes granulometrias, foi realizada uma inspeção visual para verificar o sentido da trinca em relação a direção do carregamento da força de compressão e também o tamanho das trincas na superfície do corpo de prova, uma vez que essas condições influenciam na resistência mecânica. 
Para esta análise foram utilizadas as mesmas amostras preparadas para o ensaio de compressão na segunda etapa, antes de realizar o ensaio de compressão, todas as trincas que foram encontradas na superfície dos corpos de prova, foram medidas com auxílio de um paquímetro, para quantificar a relação de trincas por área da face no corpo de prova.

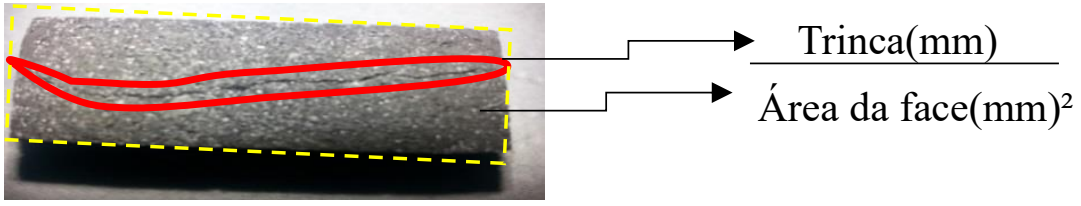

Figure 8: Avaliação das trincas/área

\section{Análise de microtextura do coque}

Foi preparado um embutimento para cada granulometria. O procedimento de preparação e análise da amostra foi realizado segundo a norma ASTM 5061 (Standard Test Method for Microscopical Determination of the Textural Components of Metallurgical Coke). Análise microscópica foi realizada em um microscópio Leica CTR 6000 equipado com o software Fóssil com um aumento de 50x (sem óleo) e com aumento de 200x. Após o polimento avançou-se para análise de microscopia, com objetiva de imersão em óleo (40x-60x), oculares 10x-12x sendo uma delas graduada, placa de retardo $(1 \Lambda)$ e contador automático de pontos para mensuração dos componentes texturais das amostras de coque, realizando-se a leitura de 500 pontos, com dimensão de cada passo de $(0,5 \mu \mathrm{m})$.

\section{RESULTADOS E DISCUSSÃO}

\section{1 - Correlação da tensão de ruptura com a densidade aparente}

O objetivo da primeira etapa dos testes de compressão foi buscar um entendimento de como a tensão de ruptura encontra-se distribuída nas diferentes faixas granulométricas, para isto buscou-se uma correlação da tensão de ruptura com as variáveis: granulometria, densidade aparente, massa, área e volume.

De acordo com a Figura 9, observou-se uma boa correlação somente entre a tensão de ruptura e a densidade aparente do coque.

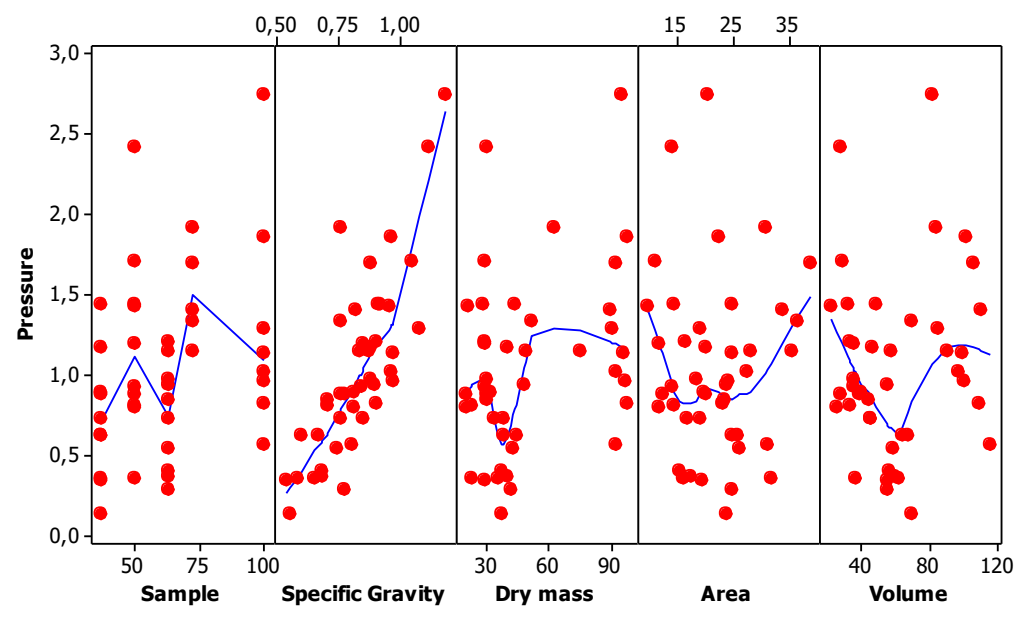

Figura 9: Correlação da tensão de ruptura com : granulometria, densidade aparente, massa, área e volume 
Isto pode ser explicado devido ao fato que o coque industrial gerado em diferentes pontos do forno de coqueificação, tanto na largura (centro ou parede) como na posição de topo ou base, influência na resistência a compressão do mesmo.

\section{2 - Correlação da tensão de ruptura com densidade aparente próxima entre todas as faixas granulometricas}

Embora se tenha observado uma boa correlação entre a resistência a compressão e a densidade aparente, conforme a Figura 10 foi demonstrado que os coques com densidade aparente próxima podem ter tensão de ruptura diferente. Isto sugeriu que para estimar a resistência a compressão do coque, é necessário elucidar o efeito das trincas e a estrutura porosa do coque.

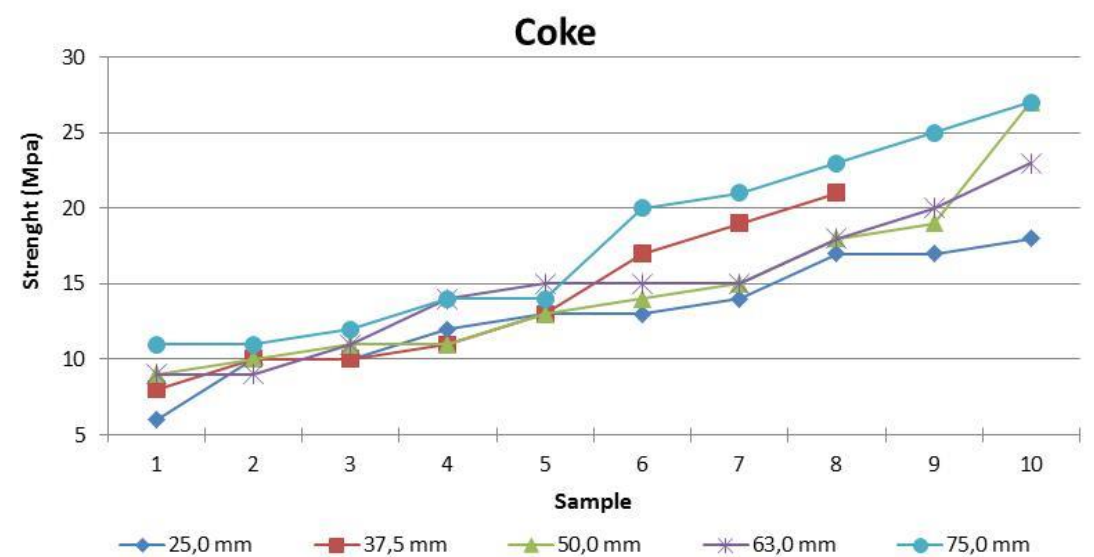

Figura 10:Correlação da tensão de ruptura com densidade aparente próximas

Segundo Tavares (2009), quanto menor a granulometria de materiais frágeis, como os coques, maior a energia específica de fratura. Sendo assim, esperava-se que as partículas com maior granulometria apresentassem maior proporção de quebra, enquanto que as de menor granulometria seriam as mais resistentes. Porém observou-se o contrário, o coque de maior granulometria $(75 \mathrm{~mm})$ apresentou as maiores tensões de ruptura, enquanto que os coques de menor granulometria $(25 \mathrm{~mm})$ apresentaram menores tensões de ruptura. Avaliando a tensão média de ruptura nas diferentes distribuições granulométricas, pode-se observar que a resistência a compressão aumenta com o aumento da granulometria, conforme a Figura 11.

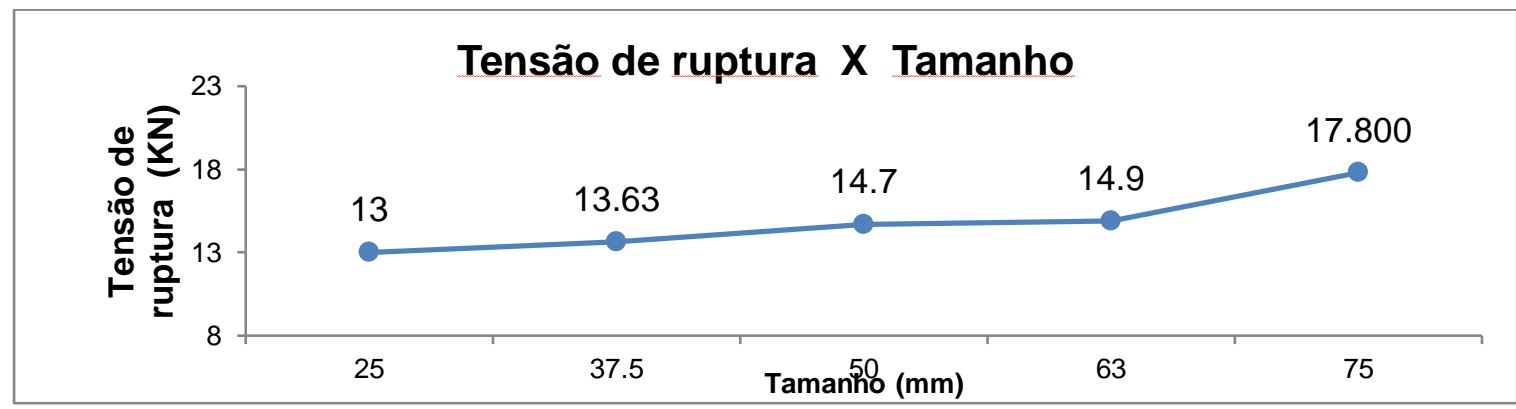

Figura 11: Correlação da tensão media de ruptura com a granulometria. 
Para o entendimento das diferenças nas tensões de ruptura é necessário estudar a distribuição dos defeitos: poros e trincas.

\section{3 - Correlação da tensão de ruptura com porosidade}

Quanto a avaliação da macroporosidade, os resultados tiveram uma boa repetibilidade segundo a norma ASTM D 167.Porém este método detecta apenas os macroporos e mesoporos, devido a tensão superficial da água não conseguir penetrar em todos os tipos de poros, especificamente nos microporos. Portanto este método avaliado de forma isolada não é suficiente para determinação da porosidade.

Com relação à avaliação da microporosidade, observou um desvio médio maior nos resultados, devido ao fato da distribuição dos microporos presentes nos corpos de prova. Conclui-se também que este método avaliado de forma isolada não é suficiente.

Portanto a análise de microporosidade e macroporosidade são complementares, isto é explicado pela razão do coque apresentar uma distribuição diferente dos tamanhos dos poros (microporos, mesoporos e macroporos), estes métodos de forma isolada não conseguem detectar todos os tipos de poros presente no coque.

Com isto conclui-se a partir dos dois métodos que a amostra de $75 \mathrm{~mm}$ apresentou maior porosidade, tanto macro quanto microporosidade

Tabela 1 : Avaliação da porosidade (Microscopio X Macroporosidade)

\begin{tabular}{|c|c|c|}
\hline Granulometria & $\begin{array}{c}\text { Microporosidade } \\
\text { Média }\end{array}$ & $\begin{array}{c}\text { Macro } \\
\text { Porosidade }\end{array}$ \\
\hline $25,0 \mathrm{~mm}$ & $18 \%$ & $49,41 \%$ \\
\hline $37,5 \mathrm{~mm}$ & $27 \%$ & $49,03 \%$ \\
\hline $50,0 \mathrm{~mm}$ & $26 \%$ & 49,26 \\
\hline $63,0 \mathrm{~mm}$ & $30,33 \%$ & 49,21 \\
\hline $75,0 \mathrm{~mm}$ & $40,67 \%$ & 49,67 \\
\hline
\end{tabular}

\section{4 - Mev}

A análise no MEV foi necessária para complementar a qualidade da estrutura porosa, como a distribuição e tamanho dos poros e a rugosidade da superfície .

A partir da análise das imagens do MEV, observou como as diferentes granulometrias também apresentam diferentes estruturas de poros ao longo da matriz. Esta diferença na microestrutura pode ser explicada devido ao fato que durante o processo de coqueificação, a carbonização progride da parede para o centro do forno fazendo com que o efeito da diferença de pressão de coqueificação gere poros com formas distorcidas.

A heterogeneidade na estrutura dos poros acaba influenciando na heterogeneidade da resistência do coque. Através das imagens da figura 13 pode-se observar que os poros presentes nas amostras de 25,0 e $37,5 \mathrm{~mm}$; se apresentam na forma alongada, enquanto que os poros das amostras com granulometria maior 
que 50,0mm apresentam na forma circular, esta característica influencia na resistência mecânica, pois os poros elípticos podem atuar como fissuras, enquanto que os circulares podem atuar como alívio de tensão.

Analisando as imagens do MEV nas diferentes faixas granulométricas, podese observar que:

-Com o aumento da granulometria pode-se observar um aumento na porosidade

-As amostras maiores que $50 \mathrm{~mm}$, os poros são mais superficiais ao longo da matriz, diferente das amostras de 25 e $37,5 \mathrm{~mm}$ que os poros são mais profundos ao longo da matriz.

-Com relação a presença das trincas, estas tornam-se mais claras conforme se tem o aumento da granulometria, tornando mais evidente nas amostras de $50 \mathrm{~mm}$, 63 e $75 \mathrm{~mm}$.
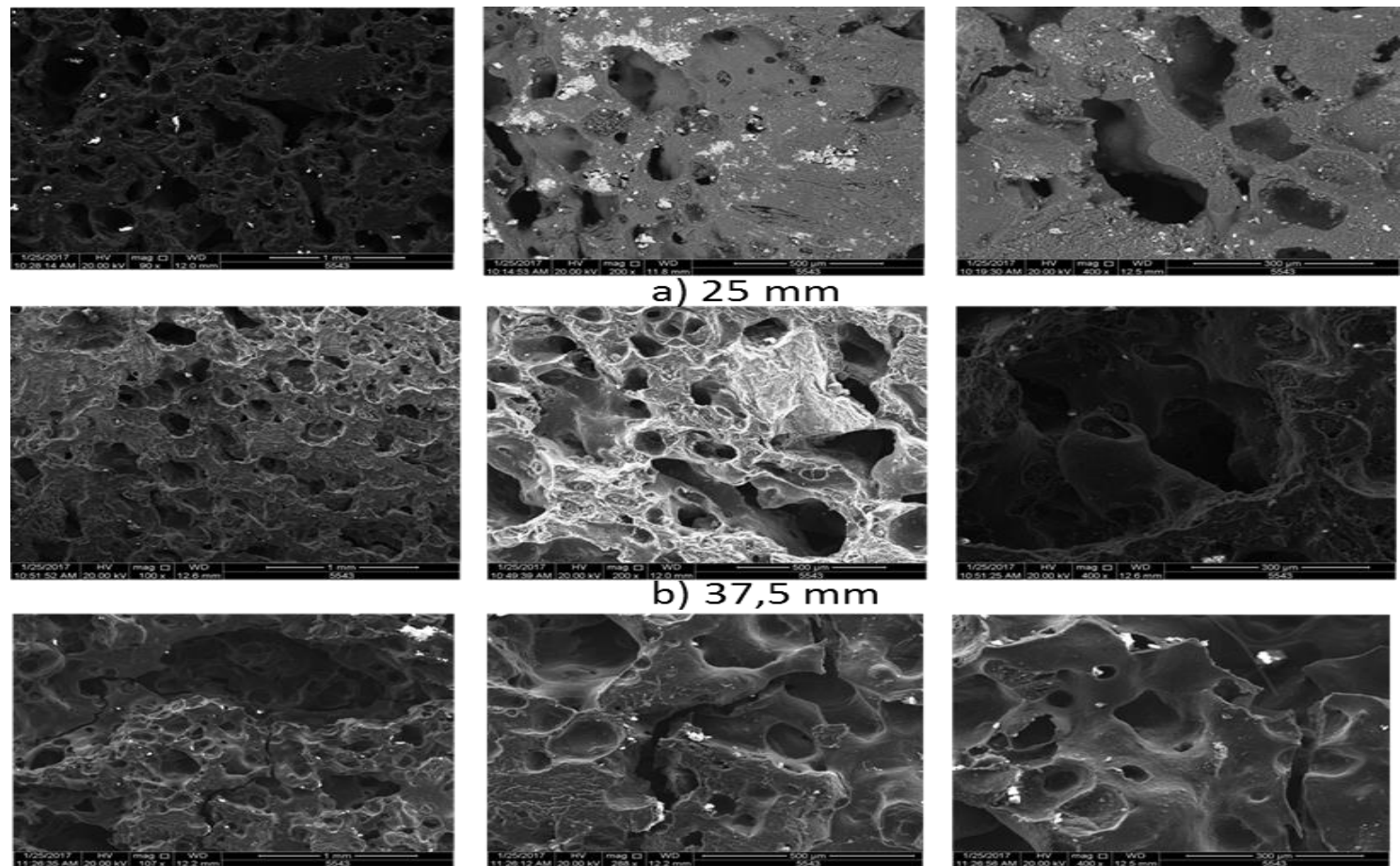

c) $50 \mathrm{~mm}$
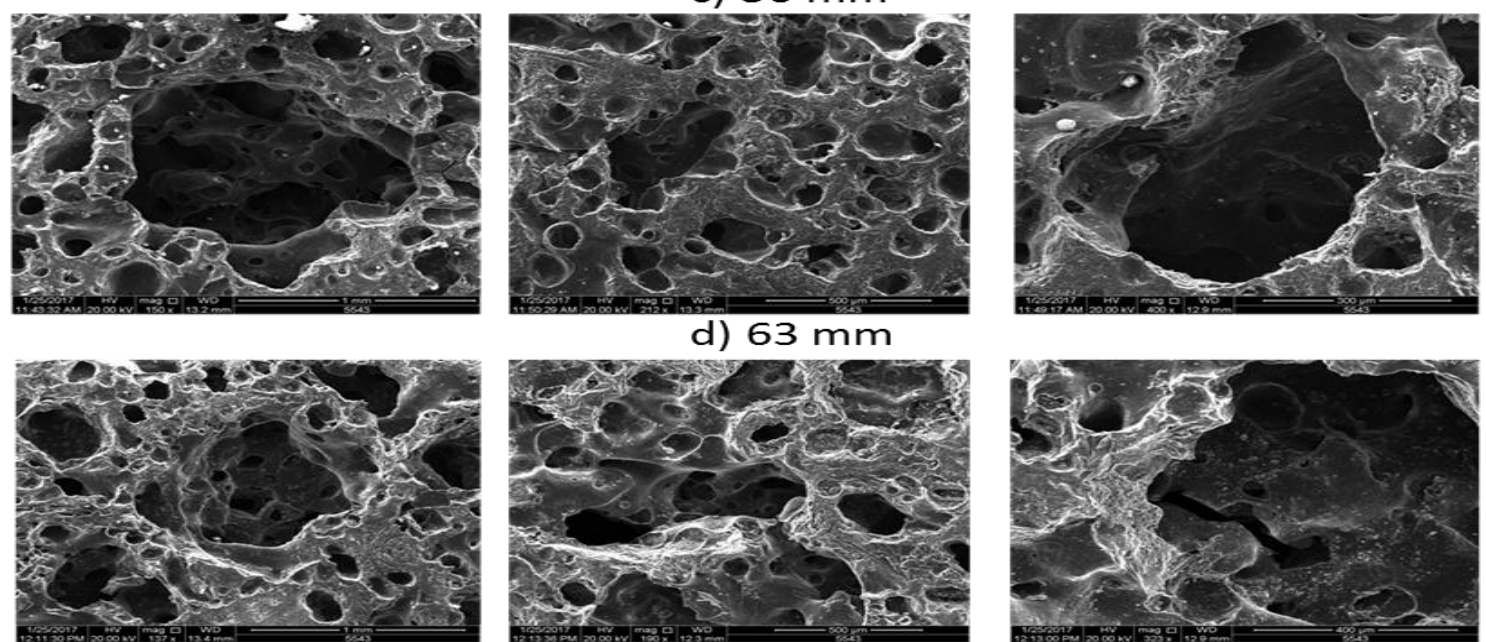

e) $75 \mathrm{~mm}$

Figura 13: Imagens do MEV nas granulometrias 25; 37.5; 50; 63; 75mm 


\section{5 - Análise de trincas}

Outro defeito que governa a resistência do coque é a presença de trincas. Quanto a sua distribuição, pode-se observar que com o aumento da granulometria , tem-se um aumento de trincas, isto fica mais evidente quando consideramos 0 tamanho médio das trincas, como pode ser visto na Figura 14.

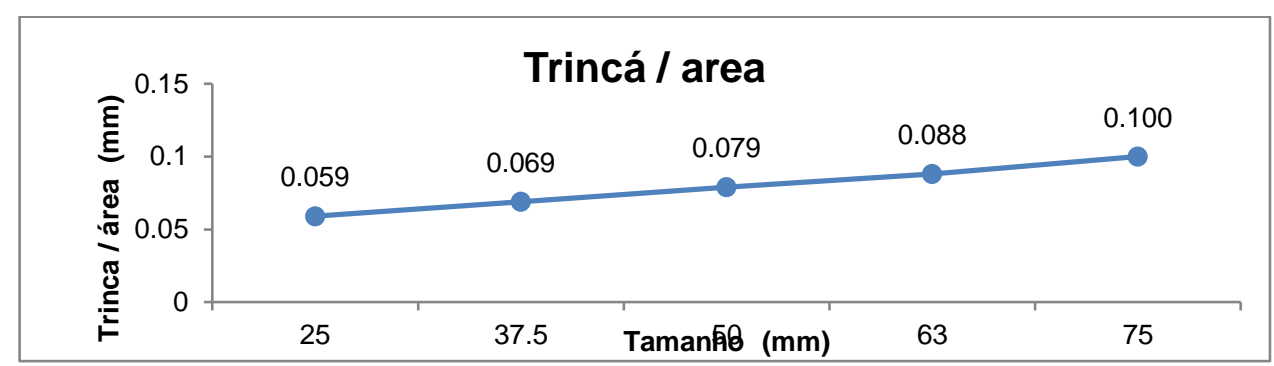

Figura 14: Tamanho médio das trincas em diferentes granulometrias

Um fato relevante na resistência a compressão em coques com trincas, é o sentido da trinca com relação a direção de carregamento da força de compressão, ou seja, se a trinca estiver perpendicular a direção do carregamento, ela não vai se propagar pois os lados se aproximam, caso contrário, se a trinca estiver paralela a direção do carregamento, ela tenderá a se propagar pois os lados tendem a se afastar.

\section{6 - Microtextura}

A análise de microtextura foi realizada porque a composição das paredes do coque, descrita pela microtextura, pode influenciar sobre as propriedades mecânicas do coque. Em relação à análise de microtextura, os testes foram inconclusivos.

De acordo com a Tabela 2, houve uma pequena variação entre as texturas encontradas nas diferentes granulometrias. Outro fator importante é que a fronteira entre os componentes ópticos da textura do coque, pode contribuir tanto para o aumento da resistência do coque, para este caso as fronteiras atuam como pontos de alívio de tensão interna, evitando a propagação de trincas, quanto para a diminuição da resistência porque as interfaces entre os grãos podem atuar como concentradores de tensão, reduzindo a resistência do coque.

Portanto as relações entre microtextura e a resistência mecânica a compressão do coque são complexas, sendo que os fatores ligados a sua microestrutura (formato, tamanho, espessura da parede dos poros) são fatores dominantes sobre a resistência mecânica final do coque

Tabela 2 :Avaliação da microtextura

\begin{tabular}{|c|c|c|c|c|c|}
\hline Textura & \multicolumn{5}{|c|}{ Tamanho } \\
\hline & $25,0 \mathrm{~mm}$ & $37,5 \mathrm{~mm}$ & $50,0 \mathrm{~mm}$ & $63,0 \mathrm{~mm}$ & $75,0 \mathrm{~mm}$ \\
\hline Mosaico Thick & $52,4 \%$ & $37 \%$ & $56 \%$ & $54 \%$ & $58 \%$ \\
\hline Thin Mosaico & $0,6 \%$ & $21 \%$ & $10 \%$ & $1 \%$ & $6 \%$ \\
\hline Banda & $12,2 \%$ & $17 \%$ & $10 \%$ & $16 \%$ & $13 \%$ \\
\hline Inerte & $5,6 \%$ & $12 \%$ & $13 \%$ & $7 \%$ & $11 \%$ \\
\hline Lenticular & $17,8 \%$ & $11 \%$ & $11 \%$ & $0 \%$ & $12 \%$ \\
\hline
\end{tabular}




\section{CONCLUSÃO}

A partir deste trabalho constatou-se a contribuição de cada granulometria do coque metalúrgico para o papel estrutural que o mesmo desempenha no Alto-Forno.

Era esperado que o coque de maior granulometria fosse o menos resistente e o de menor granulometria fosse o mais resistente, porém a partir da análise dos dados acima foi concluído o oposto, devido a razão que os defeitos como poros e trincas governam a resistência a compressão do material. $O$ coque de $75 \mathrm{~mm}$ apresentou a maior tensão de ruptura, maior tamanho médio das trincas e maior porosidade, está maior resistência a compressão, pode ser explicada devido ao fato que poros e trincas, podem dissipar a energia de deformação, interrompendo o crescimento da trinca responsável pela ruptura do sólido. Como pode ser observado na Figura 13 algumas trincas tiveram sua propagação interrompida devido a presença de poros, estes funcionaram como alivio de tensão, fazendo com que o material absorva mais energia, aumentando sua tensão de ruptura.

\section{REFERÊNCIAS}

1 King, R. P., Modeling and simulation of mineral processing systems, Oxford, Butterworth-Heinemann , 2001.

2 Silveira. M.A.C.W.,Modeling the degradation of iron ore pellets during handling and transportation. Masters dissertation PEMM/COPPE- UFRJ. Rio of Janeiro. Brazil, 2012.

3 Tavares, L.M.M., Microscale investigation of particle breakage applied to the study of thermal and mechanical predamage, doctoral thesis, University of Utah, EUA,1997.

4 Tavares, L. M. \& CARVALHO, R. M. , Modeling breakage rates of coarse particles in ball mills. Minerals Engineering,2009.

5 Carvalho, R.M., Tavares, L. M., Predictiing the effect of operating and design variables on breakage rates using the mechanistic ball mil model , 2013.

6 Coin, C. D. A., A coke microtextural comparation, and method, Fuel, 1987

7 Gray, R.J., Devanney., Coke carbono forms: microscopic classification and industrial applications, International Journal of coal Geology, 1986.

8 Hiroshi. Sato, "Strenght of metallurgical coke in relation to fissure formation" , 1999

9 Antônio. Siva, "Study of the mechanical degradation of small amounts of coke in tumbling tests, Rede Temática em Engenharia dos Materiais, 2017

10 Bruno, D. F., Experimental evaluation in a pilot furnace of the influence of a Colombian coal of high heterogeneity and of high and volatile coal coals in coke quality, 2014. 